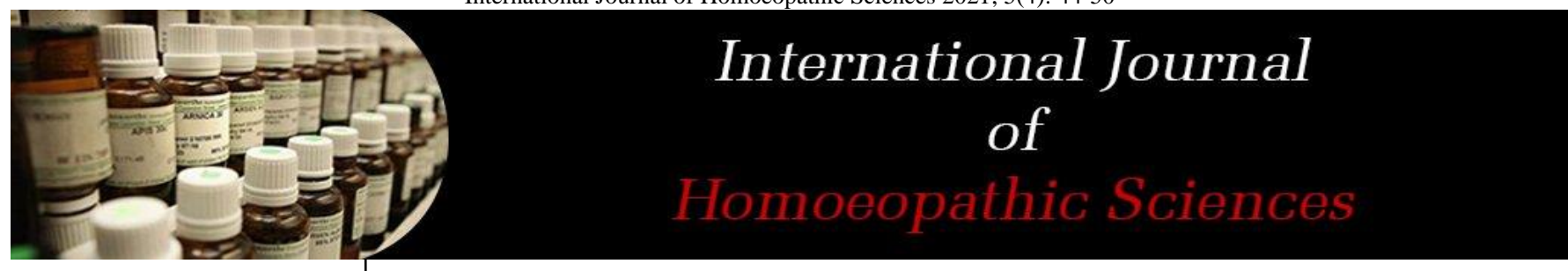

E-ISSN: $2616-4493$ P-ISSN: 2616-4485 www.homoeopathicjournal.com IJHS 2021; 5(4): 44-50

Received: 22-08-2021

Accepted: 24-09-2021

Dr. Nisha CN

Lecturer, Department of

Casetaking and

Repertorisation,

Athurasramam NSS

Homoeopathic Medical

College, Kerala University of

Health Sciences, Kerala, India

Corresponding Author:

Dr. Nisha CN

Lecturer, Department of

Casetaking and

Repertorisation,

Athurasramam NSS

Homoeopathic Medical

College, Kerala University of

Health Sciences, Kerala, India

\section{Homoeopathy in psoriasis vulgaris: A case report}

\author{
Dr. Nisha CN
}

DOI: $\underline{\text { https://doi.org/10.33545/26164485.2021.v5.i4a.452 }}$

\begin{abstract}
Psoriasis is a chronic, noncontagious immune-mediated skin disorder that has extensive physical, emotional, and psychosocial effects on patients. The common challenges for persons with psoriasis include disfiguration, disability, and marked loss of productivity. As per current knowledge, it has no cure and it is managed with topical therapy, phototherapy, and systemic treatment. This case report serves to show the role of individualized homoeopathic treatment in psoriasis. In the case of a 23-yearold male patient with psoriasis vulgaris, the homoeopathic remedy Psorinum was given in $200 \mathrm{C}$ potency after repertorising the totality of symptoms in Synthesis repertory using RADAR software. The outcome analysis was done using changes in clinical symptoms and improvement in the general well being of the patient. The dermatology life quality index improved from a score of 24 to 0 during treatment. The MONARCH score of $+9 / 13$ shows a positive causal relationship between Psorinum and the treatment outcome.
\end{abstract}

Keywords: psoriasis vulgaris, case report, homoeopathy, dermatology life quality index, monarch criteria

\section{Introduction}

Psoriasis is a chronic inflammatory, hyperproliferative skin disease. It is characterised by well-defined, erythematous scaly plaques, particularly affecting extensor surfaces and scalp, and usually follows a relapsing and remitting course ${ }^{[1]}$. It has no cure and it is with a great negative impact on patients' quality of life. It can occur at any age and is most common in the age group 50-69. The prevalence of psoriasis ranges between $0.09 \%$ and $11.4 \%$, making psoriasis a serious global problem ${ }^{[2]}$. It is generally thought to be a genetic disease that is triggered by environmental factors ${ }^{[3]}$. Psoriasis can also be provoked by external and internal triggers, including mild trauma, sunburn, infections, systemic drugs and stress ${ }^{[2]}$. Psoriasis vulgaris (also known as chronic stationary psoriasis or plaque-like psoriasis) is the most common form and affects $85-90 \%$ of people with psoriasis. Plaque psoriasis typically appears as raised areas of inflamed skin covered with silvery-white, scaly skin. These areas are called plaques and are most commonly found on the elbows, knees, scalp, and back ${ }^{[4]}$. Additional types of psoriasis comprise about $10 \%$ of cases. They include pustular, inverse, napkin, guttate, oral, and seborrheic-like forms ${ }^{[5]}$. Psoriasis is characterized by the abnormally excessive and rapid growth of the epidermal layer of the skin. Abnormal production of skin cells and an overabundance of skin cells result from the sequence of pathological events in psoriasis ${ }^{[6]}$.

A diagnosis of psoriasis is usually based on the appearance of the skin. Skin characteristics typical for psoriasis are scaly, erythematous plaques, papules, or patches of skin that may be painful and itch. No special blood tests or diagnostic procedures are usually required to make the diagnosis ${ }^{[7,8]}$. If the clinical diagnosis is uncertain, a skin biopsy or scraping may be performed to rule out other disorders and to confirm the diagnosis. Skin from a biopsy shows clubbed epidermal projections that interdigitate with dermis on microscopy ${ }^{[7,9]}$.

Psoriasis causes great physical, emotional and social burdens. Quality of life, in general, is often significantly impaired. There is also a significant cost to mental well-being, such as higher rates of depression, leading to negative impacts for individuals and society. Social exclusion, discrimination and stigma are psychologically devastating for individuals suffering from psoriasis and their families ${ }^{[2]}$. The current understanding of psoriasis is that it is an inherited autoimmune disease that can be suppressed by current therapies rather than cured. Management comprises avoidance of known exacerbating factors (smoking, alcohol), using topical preparations, undertaking phototherapy or photo chemotherapy and taking systemic therapy ${ }^{[10]}$. 
The Dermatology Life Quality Index questionnaire (DLQI) consists of 10 questions concerning patients' perception of the impact of skin diseases on different aspects of their health-related quality of life over the last week. It is designed for use in adults (patients over the age of 16). The DLQI is calculated by summing the score of each question resulting in a maximum of 30 and a minimum of 0 . The higher the score, the more quality of life is impaired [11,12,13].

This case report shows a case of psoriasis vulgaris treated with individualised homoeopathic medicine with improvement in the quality of life of the patients. There were many studies showing the role of homoeopathy in the management of psoriasis ${ }^{[14,15]}$ in an effective and harmless way.

\section{Methods}

This is a case of psoriasis vulgaris treated with individualized homeopathy medicine. Systematic case taking followed by repertorisation of the totality of symptoms has been done in Synthesis repertory using RADAR Software ${ }^{[16]}$ in order to choose the individualized remedy. Case reporting has been done according to the HOM-CASE guidelines, an extension of CARE guidelines [17]. The causal relation between the Clinical improvement and the medicine prescribed was assessed using the Monarch Inventory ${ }^{[18]}$ (Improved version of the modified Naranjo criteria for Homoeopathy).

\section{Case presentation}

A male patient of 23 years old from Aluva came to the outpatient department of Athurasramam NSS Homoeopathic hospital, Kottayam on 3/12/2020 was presenting with scaly itching eruptions all over the body which on scratching leads to bleeding and soreness of the parts. Complaint associated with the sensation of the heat of the body, offensiveness and general weakness. Scaly eruptions < sun exposure, night $>$ daytime. The patient had scaly dandruff on the scalp since puberty, especially on the hair margins. Gradually lesions started appearing on all other parts of the body about 5 years back. He took allopathic treatment for about 1 year and got no relief, so changed to Ayurveda treatment from which got a temporary relief and then switched to homoeopathic treatment. In past history of illness, he had mumps at 16 years of age which got relieved by allopathy treatment. Nothing relevant in family history.

\section{Life space investigation}

He was born in a middle-class family. His father is a watchman and his mother is a shopkeeper. He has a younger brother. When doing the ITI welding course at 17 years of age, he had many friends and he started the habit of drinking alcohol and tobacco smoking. After completing the course he started working in a welding center. Soon after that he noticed his first lesion but neglected it but the complaint aggravated gradually and his friends started avoiding him fearing that he has a contagious skin disorder that affected him so deeply, so he quitted his job. His family could not afford the treatment expenses, so his younger brother started working to meet this situation which had made the patient sadder.

\section{Mental generals}

Fear of heights, Despair of his skin complaint and Forsaken feeling.

\section{Physical generals}

$\mathrm{He}$ has diminished appetite, intolerance to pork, sleep disturbed due to itching, and hard stool. General < night, sun exposure.

Upon physical examination his height was found as $165 \mathrm{~cm}$, weight as $45 \mathrm{~kg}$, pulse 68/minute, BP $120 / 80 \mathrm{~mm}$ of $\mathrm{Hg}$. On examination of the skin, diffuse lesions of varying size were noted all over the body with scaling and offensiveness of the body. Lesions were with irregular and slightly raised borders and edema was absent. Auspitz sign was positive. The diagnosis was done by the clinical findings, the characteristic appearance of the lesions, and positive Auspitz sign.

\section{Totality of symptoms}

Despair from skin complaints

Forsaken feeling

Fear of heights

Appetite diminished

Intolerance to pork

Hard, bloody stool

Sleep disturbed

General <night, sun exposure

General weakness of the body

Offensiveness of whole body

scaly itching eruption

Sensation of heat of the body

\section{Repertory analysis}

Repertorisation was done in RADAR 10 software using Synthesis treasure edition, 2007 by Fredericke Schroyens [16]. 


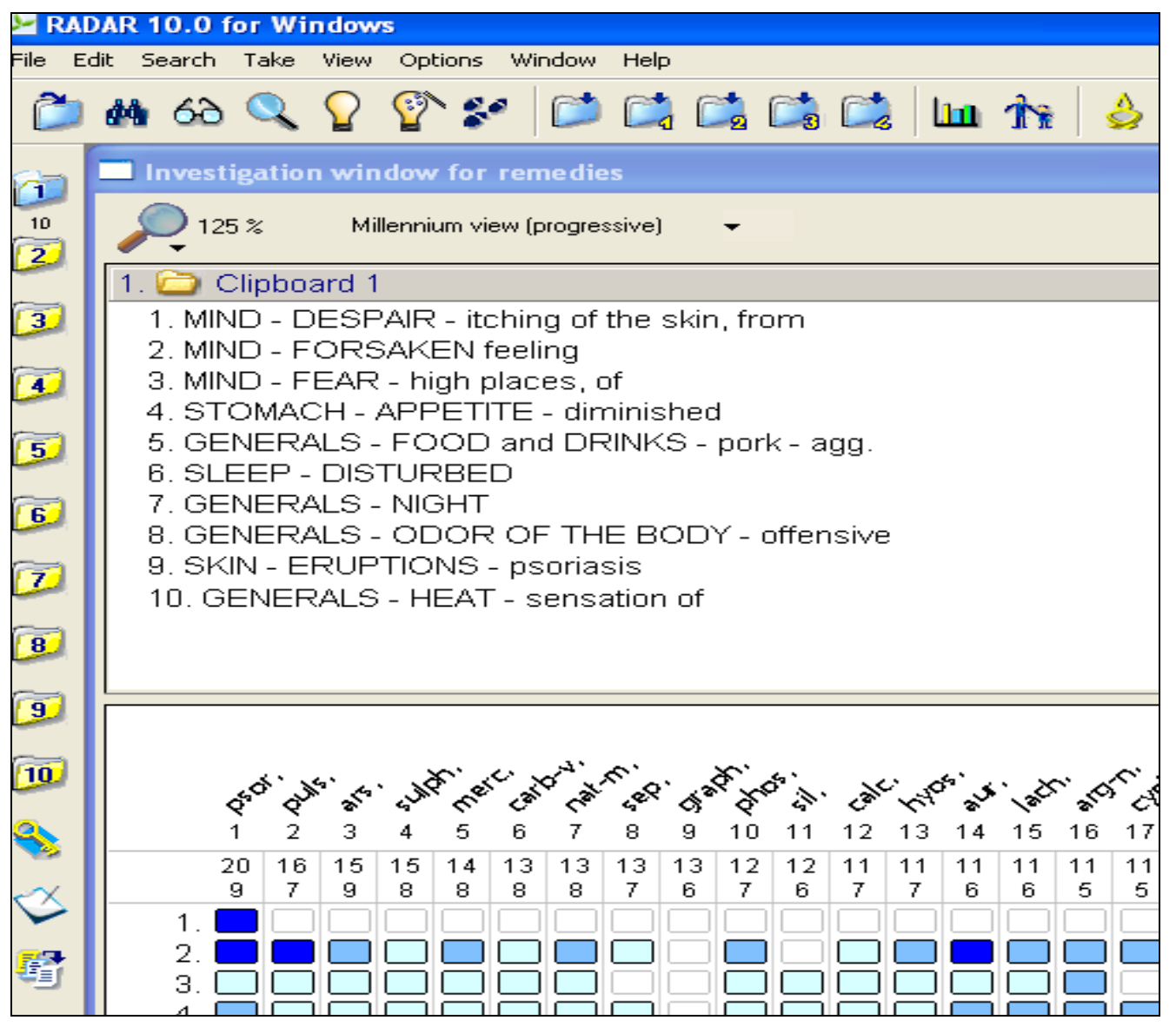

Repertorial result

Psorinum 20/9

Pulsatilla 16/7

Arsenicum album 15/9
Sulphur $15 / 8$

Mercurius solubilis 14/8

Natrum muriaticum $13 / 8$

Table 1: Timeline of treatment

\begin{tabular}{|c|c|c|}
\hline Date & Observation & Management \\
\hline $3-12-2020$ & $\begin{array}{c}\text { Itching, scaly lesions on various parts of the body } \\
\text { General weakness } \\
\text { Soreness and pain over the parts } \\
\text { Offensiveness of the body }\end{array}$ & Rx, Psorinum 200/1 dose \\
\hline $21-1-2021$ & $\begin{array}{c}\text { Itching- relieved } \\
\text { No new lesions } \\
\text { Better for older lesions } \\
\text { General weakness } \\
\text { Soreness ameliorated }\end{array}$ & Rx, Sac Lac/1 dose \\
\hline $11-2-2021$ & $\begin{array}{c}\text { Soreness of thighs with burning } \\
\text { Appearance of new lesions }\end{array}$ & Rx, Psorinum 200/1 dose \\
\hline $22-4-2021$ & $\begin{array}{c}\text { Skin eruptions relieved } \\
\text { No new lesions } \\
\text { Complaints relieved }\end{array}$ & Rx, Sac Lac/1 dose \\
\hline $10-6-2021$ & $\begin{array}{c}\text { Complaints relieved } \\
\text { Dermatology quality of life index was again analyzed which showed a score of } 0 .\end{array}$ & Rx, Sac Lac/1 dose \\
\hline
\end{tabular}

Dermatology life quality index score before the treatment was found as 24 which indicated that the disease had an extremely large effect on patient's life which reduced to a score of 0 after the treatment.

\footnotetext{
Dermatology Life Quality Index (DLQI) ${ }^{[11,12,13]}$

Hospital - ANSS HMC

Name - Mr. X

Date $-3 / 12 / 2021$

Diagnosis - Psoriasis
}

The aim of this questionnaire is to measure how much your skin problem has affected your life over the last week. Please tick $(\checkmark)$ one box for each question.

1. Over the last week, how itchy, sore, painful or stinging has your skin been?

Very much

A lot

A little

Not at all 
2. Over the last week, how embarrassed or self-conscious have you been because of your skin?

Very much

A lot

A little

Not at all

3. Over the last week, how much has your skin interfered with you going shopping or looking after your home or garden?

Very much

A lot

A little

Not at all

Not relevant

4. Over the last week, how much has your skin influenced the clothes you wear?

Very much

A lot

A little

Not at all

Not relevant

5. Over the last week, how much has your skin affected any social or leisure activities?

Very much

A lot

A little

Not at all

Not relevant

6. Over the last week, how much has your skin made it difficult for you to do any sport?

Very much

A lot

A little

Not at all

Not relevant

7. Over the last week, has your skin prevented you from working or studying?

Yes

No

Not relevant
If "No", over the last week how much has your skin been a problem at work or studying?
A lot
A little
Not at all

8. Over the last week, how much has your skin created problems with your partner or any of your close friends or relatives?

Very much

A lot

A little

Not at all

Not relevant

9. Over the last week, how much has your skin caused any sexual difficulties?

Very much

A lot

A little

Not at all

Not relevant

10. Over the last week, how much of a problem has the treatment for your skin been, for example by making your home messy, or by taking up time?

Very much

A lot

A little

Not at all

Not relevant

\section{Scoring}

The scoring of each question is as follows:

Very much scored 3

A lot scored 2

A little scored 1

Not at all scored $\quad 0$

Not relevant scored 0

Question 7, 'prevented work or studying' scored 3

The monarch score of $+9 / 13$ (Table-2) indicates that the improvement attributed to the Homoeopathic medicine Psorinum.

Table 2: Monarch Inventory ${ }^{[17]}$ (improved version of the Modified Naranjo criteria for Homoeopathy)

\begin{tabular}{|c|c|}
\hline Domain & Score \\
\hline Was there an improvement in the main symptom or condition for which the homeopathic medicine was prescribed? & +2 \\
\hline Did the clinical improvement occur within a plausible timeframe relative to the medicine intake? & +1 \\
\hline Was there a homeopathic aggravation of symptoms? & 0 \\
\hline $\begin{array}{c}\text { Did the effect encompass more than the main symptom or condition (i.e., were other symptoms, not related to the main presenting } \\
\text { complaint, improved or changed)? }\end{array}$ & +1 \\
\hline $\begin{array}{c}\text { Did overall well-being improve? } \\
\text { (Suggest using a validated scale or mention about changes in physical, emotional, and behavioural elements) }\end{array}$ & +1 \\
\hline $\begin{array}{c}\text { Did "old symptoms" (defined as non-seasonal and non-cyclical symptoms that were previously thought to have } \\
\text { resolved) reappear temporarily during the course of improvement? }\end{array}$ & 0 \\
\hline $\begin{array}{c}\text { Are there alternative causes (i.e., other than the medicine) that-with a high probability-could have produced the improvement? } \\
\text { (Consider known course of disease, other forms of treatment, and other clinically relevant }\end{array}$ & +1 \\
\hline Was the health improvement confirmed by any objective evidence? (e.g., investigations, clinical examination, etc.) \\
\hline Did repeat dosing, if conducted, create similar clinical improvement? \\
\hline Total Score \\
\hline
\end{tabular}




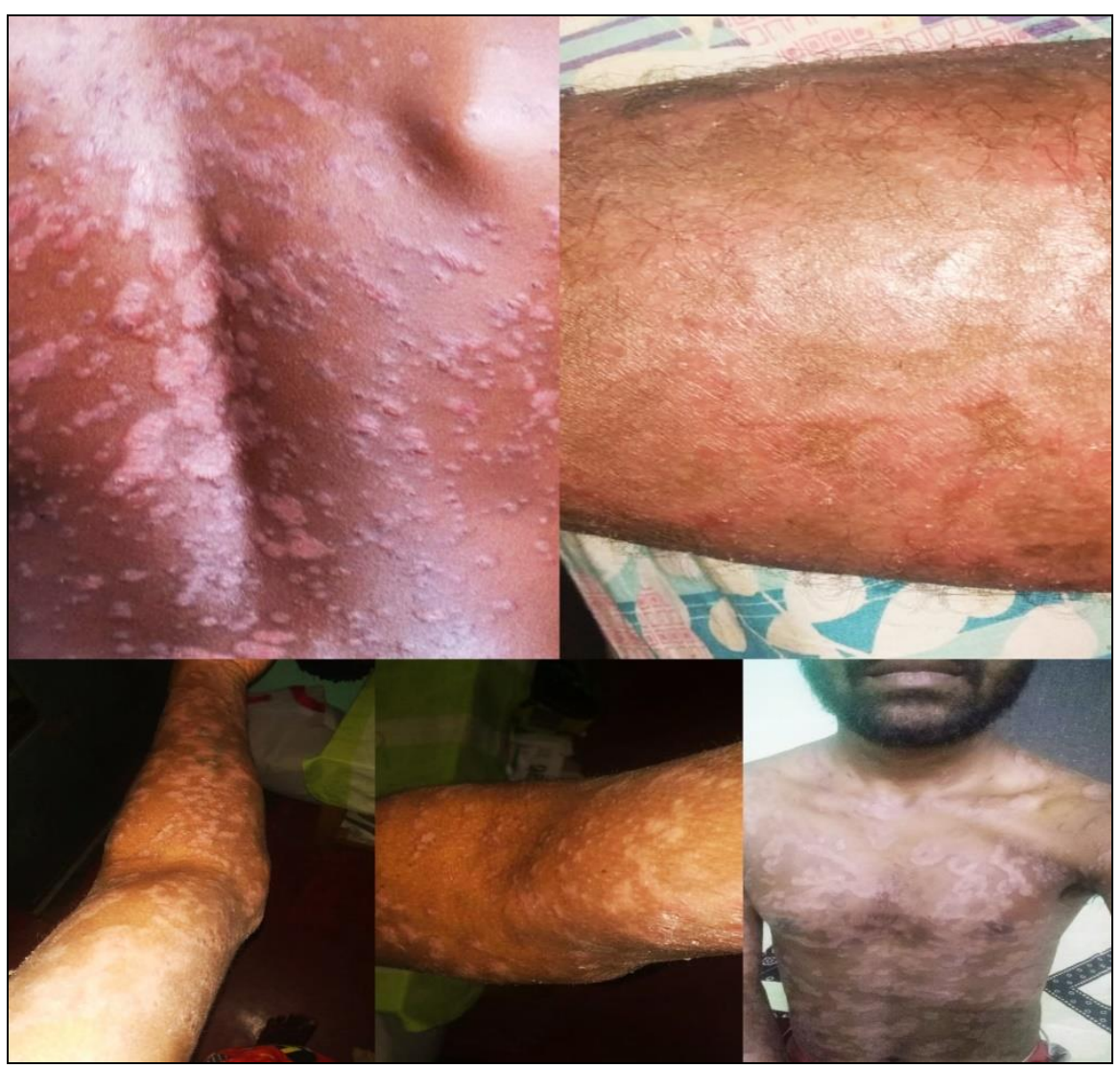

Fig 1: Before treatment

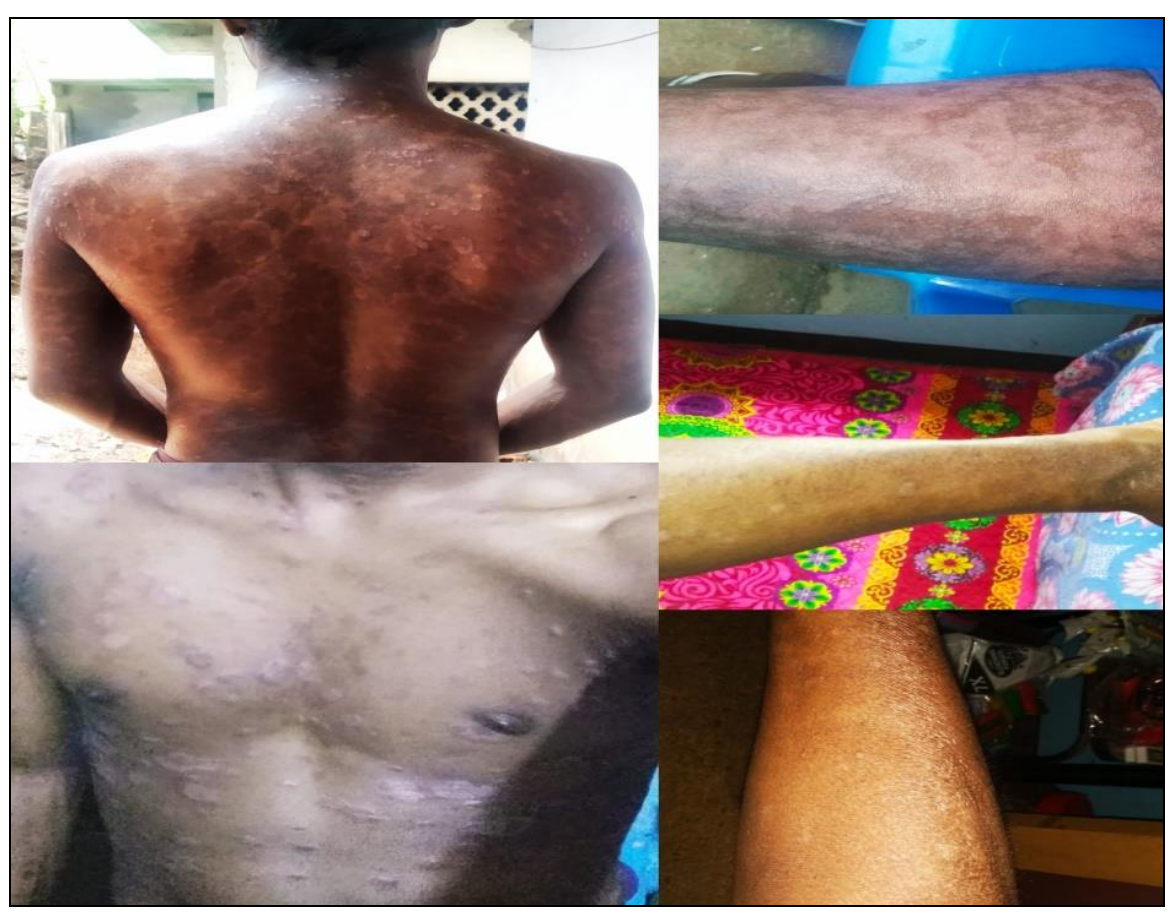

Fig 2: During treatment 


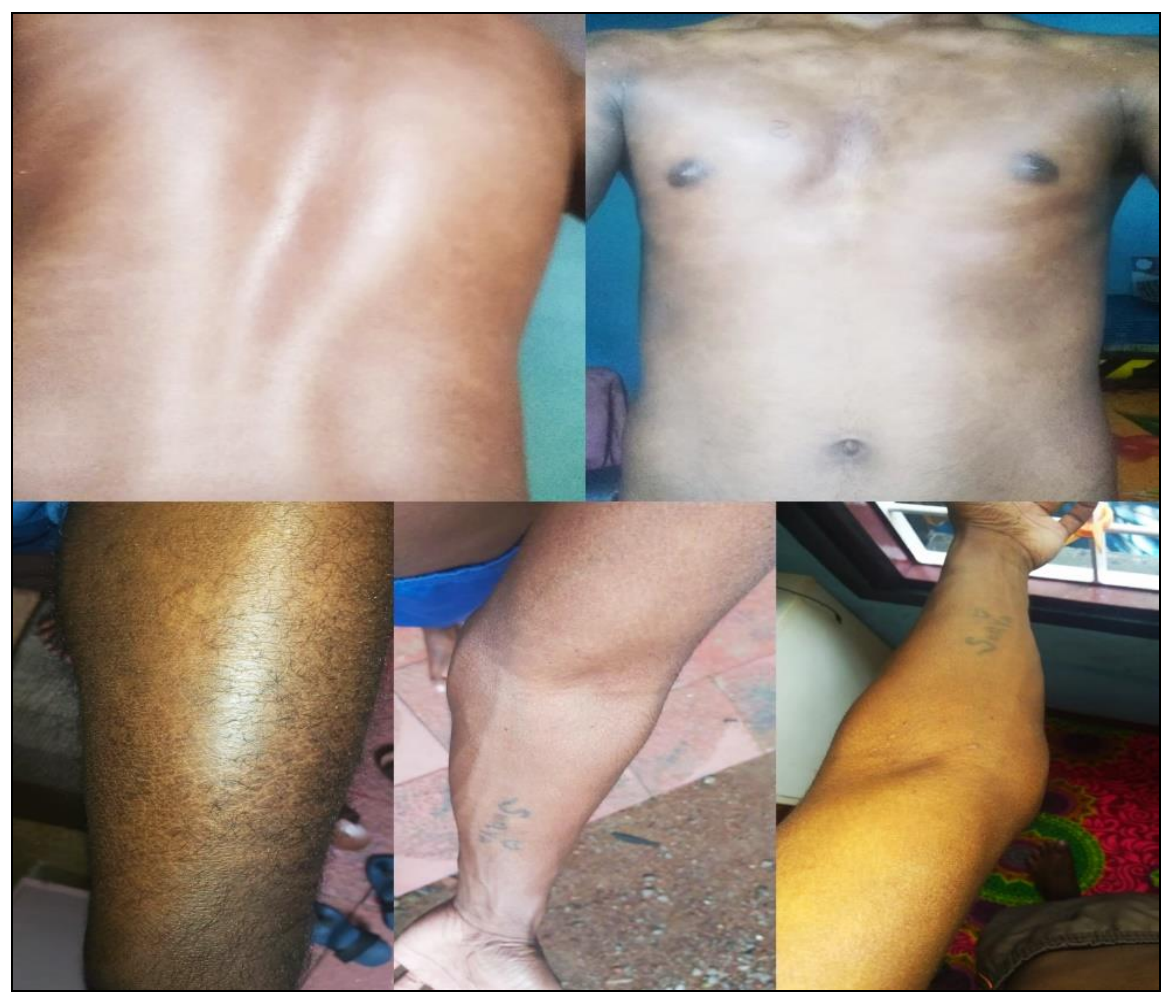

Fig 3: After treatment

\section{Results}

The above case of psoriasis vulgaris with lesions over whole body with intensive itching and soreness was treated with the individually selected homoeopathic remedy Psorinum in $200 \mathrm{C}$ potency. The outcome was analysed by changes in clinical presentation along with improvement in general wellbeing. The dermatology life quality index Score improved from 24 to 0 during treatment. MONARCH score of $+9 / 13$ indicates a positive causal relationship between the Homoeopathic medicine Psorinum and the clinical outcome.

\section{Discussion}

This case report intends to show the role of homeopathic constitutional remedies in Psoriasis vulgaris which is characterized by relapses and remissions and with a negative impact on the physical and mental plane of the patient. Both the clinical symptoms and quality of life of the patient can be improved by a well-selected homeopathic remedy chosen after systematic case taking. In a prospective multicentre observational study done it is concluded that, under homeopathic treatment, the severity of psoriasis and accompanying diseases, as well as quality of life improved substantially and the uses of conventional medication and health services decreased markedly ${ }^{[19]}$. There are many case reports showing the usefulness of individualized homeopathy treatment in psoriasis cases ${ }^{[20,21,22]}$.

\section{Conclusion}

The present case report of psoriasis vulgaris treated with homoeopathic constitutional medicine aids as a valuable clinical study in such cases although conclusions should be made from further systematic studies.

\section{Declaration of patient consent}

A written informed consent was taken from the patient to use his clinical information and images to be reported in the journal.

\section{References}

1. Walker BR, Colledge NR, Ralston S, Penman ID, Britton R, editors. Davidson's principles and practice of medicine. 22nd edition. Edinburgh; New York: Churchill Livingstone/ Elsevier 2014, 1286-1289p.

2. Global report on psoriasis - WHO Library Cataloguingin-Publication. ISBN 9789241565189 (NLM classification: WR 205) World Health Organization 2016-available from apps.who.int > iris > bitstream.

3. Menter A, Gottlieb A, Feldman SR, Van Voorhees AS, Leonardi CL, Gordon KB, et al. "Guidelines of care for the management of psoriasis and psoriatic arthritis: Section 1. Overview of psoriasis and guidelines of care for the treatment of psoriasis with biologics". Journal of the American Academy of Dermatology 2008, 58(5). PMID 18423260.

4. Palfreeman AC, McNamee KE, McCann FE (March). "New developments in the management of psoriasis and psoriatic arthritis: a focus on apremilast". Drug Design, Development and Therapy 2013. PMC 3615921. PMID 23569359.

5. James William, Berger Timothy, Elston Dirk. Andrews' Diseases of the Skin: Clinical Dermatology (10th ed.). Saunders 2005, 191-7. ISBN 978-0-7216-2921-6.

6. Ouyang W. "Distinct roles of IL-22 in human psoriasis and inflammatory bowel disease". Cytokine \& Growth Factor Reviews 2010;21(6):435-41. doi:10.1016/j.cytogfr.2010.10.007. PMID 21106435

7. Raychaudhuri SK, Maverakis E, Raychaudhuri SP. (January). "Diagnosis and classification of psoriasis". Autoimmunity Reviews 2014;13(4-5):490-5. doi:10.1016/j.autrev. 2014.01.008. PMID 24434359

8. Johnson MA, Armstrong AW. "Clinical and histologic diagnostic guidelines for psoriasis: a critical review". Clinical Reviews in Allergy \& Immunology 2013;44(2):166-72. Doi:10.1007/s12016012-8305-3. PMID 22278173. S2CID 42148834 
9. Kunz M, Ibrahim SM. Cytokines and cytokine profiles in human autoimmune diseases and animal models of autoimmunity. Mediators of Inflammation 2009. 979258. doi:10.1155/2009/979258. PMC 2768824. PMI D 19884985

10. Rachael Morris-Jones- ABC of dermatology- $6^{\text {th }}$ edition-London, UK 2014, 18.

11. Finlay AY, Khan GK. Dermatology Life Quality Index (DLQI): a simple practical measure for routine clinical use. Clin Exp Dermatol 1994;19:210-216.

12. Basra MK, Fenech R, Gatt RM, Salek MS, Finlay AY. The Dermatology Life Quality Index 1994-2007: a comprehensive review of validation data and clinical results. Br J Dermatol 2008;159:997-1035.

13. Hongbo Y, Thomas CL, Harrison MA, Salek MS, Finlay AY. Translating the science of quality of life into practice: What do dermatology life quality index scores mean? J Invest Dermatol 2005;125:659-64.

14. Witt CM, Lüdtke R, Willich SN. Homeopathic treatment of patients with psoriasis--a prospective observational study with 2 years follow-up- Journal of the European academy of dermatology and venereology 2009;23(5):538-43. doi: 10.1111/j.1468 3083.2009. 03116.x. Epub 2009 Feb 2.PMID: 19192019. DOI:

15. Mahesh S, Shah V, Mallappa M, Vithoulkas G. Psoriasis cases of same diagnosis but different phenotypes-Management through individualized homeopathic therapy- Clinical case reports2019;7(8):1499-1507. doi: 10.1002/ccr3.2197. eCollection 2019 Aug.

16. Schroyens F. synthesis Treasure edition. Radar 10 software. Archibel- Belgium 2007.

17. Van Haselen RA. Homeopathic clinical case reports: development of a supplement (HOM-CASE) to the CARE clinical case reporting guideline. Complement. Ther. Med 2016;25:78-85.

18. Lamba CD, Gupta VK, van Haselen R, Rutten L, Mahajan N, Molla AM, et al. Evaluation of the modified Naranjo criteria for assessing causal attribution of clinical outcome to homeopathic intervention as presented in case reports. Homeopathy 2020;109(04):191-7.

19. Witt CM, Lüdtke R, Willich SN. Homeopathic treatment of patients with psoriasis - a prospective observational study with 2 years follow-up- Journal compilation-European Academy of Dermatology and Venereology - JEADV 2009;23:538-543.

20. Hanuman Ram, Minakshi Kamboj. Effect of Individualized Homoeopathic medicine in Psoriasis: A Case Report- National Homoeo Recorder 2019;XV(IIIII).

21. Annu Kanwar, Hanuman Ram, Narender Kumar, Navita Bagdi. Plaque Psoriasis Successfully Treated with an Individualised Homoeopathic Medicine Lycopodium: A Case Report - Homœopathic LinksDOI: 10.1055/s-0040-1714381- Georg Thieme Verlag KG 2021.

22. Bhaskar Sarkar, Maurya Manjurani Sheopal. Psoriasis improved homoeopathically: A case reportInternational Journal of Homoeopathic Sciences 2020;4(3):24-27. 